\title{
Prevalence of Depression among Caregivers of Dementia Patients
}

\author{
Hamza $S A^{1,2}$, Raafat $V^{1,2}$, Fawzy $H^{1,2}$ and Abbass $A^{1,2}$ \\ 1Geriatrics\& Gerontology department, Faculty of Medicine, Ain Shams University, Cairo, Egypt. \\ 2Ain Shams Ageing Research Center.
}

\begin{abstract}
Background: Depression is a common problem affecting caregivers of dementia patients. Factors such as caregivers' age, gender, educational level, marital status and financial status may play a role in care giving related depressive disorder.

Aim: to detect the prevalence of depression among caregivers.

Methods: The study included 96 caregivers for demented elderly patients. Depression among caregivers was assessed using PHQ-9 scale

Results: The caregivers' mean age was $(42.94) \pm 13.17$ years. $(69.7 \%)$ of the care givers were women. More than half of them $(52 \%)$ were married. $(38.5 \%)$ of caregivers had moderate to severe depression, $(43.7 \%)$ had mild to moderate depression and $(17.7 \%)$ were with minimal depressive symptoms.

Conclusions: Caregivers of patients with dementia are prone to depression and physical ailments. Caregiver factors predicting liability to caregiver burden are caregiver's financial status, caregiver's education level among other socio-demographic variables.

Keywords: Caregiver Burden, Dementia, Depression, Female caregivers, socio-demographic status and burden.
\end{abstract}

\section{Background:}

The depressive symptoms and the burden sustained by caregivers of dementia patients have been the two most widely studied caregiving outcomes, as the association between feelings of burden and the overall caregiver role is well documented ${ }^{1}$. Several studies suggested that caregivers of dementia patients are significantly more likely to be depressed than the non-caregiver controls $^{2}$. Reports exist that many caregivers are at risk of experiencing clinical depression. Nearly half of the caregivers in some studies were reported to meet diagnostic criteria for depression when structured clinical interviews were used ${ }^{3}$.

Factors such as female gender and residing with dementia patients make the caregiver more susceptible for burden and depression ${ }^{4}$. Women represent approximately $70 \%$ of the caregiving population, and constitute $73 \%$ of those providing care for dementia patients ${ }^{5}$. Traditionally, it has been the female's social role to perform the nurturing activities for individuals who are unable to care for themselves especially within the family members ${ }^{6}$.

The aim of the current study was to quantify depression affecting the caregivers of dementia patients.

\section{Methods \\ Study population}

A cross sectional study comprised 96 primary caregivers of the demented elderly subjects, both males and females attending geriatrics and psychiatry outpatient clinics. Diagnosing dementia was done according to Diagnostic and Statistical Manual of Mental disorders IV (DSM IV) criteria

The Caregivers who suffered from any pre-caregiving psychiatric or neurologic disorder and the caregivers who didn't reside with the care-recipient were excluded 
from the study

All participants underwent detailed interview to obtain socio-demographic data. Patient Health Questionnaire 9 (PHQ-9) was used to assess depression. ${ }^{7}$

The PHQ-9 is a multipurpose instrument for screening, diagnosing, monitoring and measuring the severity of depression. PHQ-9 scores of 5, 10, 15, and 20 represents mild, moderate, moderately severe and severe depression. ${ }^{8}$

\section{Ethical consideration:}

The study methodology was reviewed and approved by the Research Review Board of the Geriatrics and Gerontology Department, Faculty of Medicine, Ain Shams University. Verbal consent was taken from every caregiver participating in this study.

\section{Statistical Analysis}

The collected data was revised, coded, tabulated and introduced to a PC using Statistical package for Social Science (SPSS 15.0.1 for windows; SPSS Inc, Chicago, IL, 2001). Data was presented and suitable analysis was done according to the type of data obtained for each parameter.

Description of all data in the form of mean (M) and standard deviation (SD) for all quantitative variables was done. Frequency and percentage was done for all qualitative variables.

\section{Results}

The study sample included 96 informal caregivers who were the primary caregivers for demented older family members. Most of them $(69.7 \%)$ were women and $(30 \%)$ were men. The caregivers' mean age was (42.94) \pm 13.17 years. More than half of them (52\%) were married and (47.9\%), were unmarried (single, widowed, divorced).

$(47.9 \%)$ of them were highly educated, while $(38.5 \%)$ completed their middle education (secondary school) and $(13.5 \%)$ were illiterate. The monthly income for $(68.7 \%)$ was enough, while $(25 \%)$ suffered from financial hardships and only $(6.3 \%)$ of them weren't suffering from any financial problems. The mean age for care recipients was $(76.72) \pm 6.41$ years.

Results also showed that $(38.5 \%)$ of caregivers had moderate to severe depression, $(43.7 \%)$ had mild to moderate depression and $(17.7 \%)$ were with minimal depressive symptoms as regard Patient Health Ouestionnaire-9 (PHO-9).

Table 1: Descriptive characteristics

\begin{tabular}{lll}
\hline \multicolumn{2}{l}{ Socio-demographic data } & \\
Age of caregiver mean (SD) & $42.94(13.71)$ \\
Age of care recipient mean (SD) & Male & $76.72(6.41)$ \\
Gender & Female & $\mathbf{2 9}(30 \%)$ \\
Marital status of & Unmarried & $46(30 \%)$ \\
caregiver & Married & $50(52 \%)$ \\
Education n (\%) & Not Educated & $13(13.5 \%)$ \\
& Middle & $37(38.5 \%)$ \\
& High & $46(47.9 \%)$ \\
Monthly income of & Hardly enough & $24(25 \%)$ \\
caregiver & Enough & $66(68.7 \%)$ \\
& Enough with ease & $6(6.3 \%)$ \\
\hline
\end{tabular}

Table 2: Caregivers' scores in PHQ-9

\begin{tabular}{lll}
\hline & Frequency & Percent \% \\
\hline Minimal depression & $\mathbf{1 7}$ & $\mathbf{1 7 . 7 \%}$ \\
Mild to Moderate depression & $\mathbf{4 2}$ & $\mathbf{4 3 . 7 \%}$ \\
& & $\mathbf{3 8 . 5} \%$ \\
\hline
\end{tabular}

Table 3: Comparison analysis between caregivers' scores in PHQ-9 and their socio-demographic characteristics:

\begin{tabular}{llll}
\hline \multirow{2}{*}{ Gender } & Male & PHQ9 & P \\
\cline { 2 - 3 } & Female & $10.83(6.54)$ & 0.013 \\
Marital & Unmarried & $14.8(7.22)$ & \\
status of & Married & $13.28(7.79)$ & 0.691 \\
caregiver & Not Educated & $13.88(6.72)$ & \\
Education $n$ & Middle & $15.31(3.17)$ & 0.081 \\
$(\%)$ & High & $11.84(7.39)$ & \\
& Hardly enough & $14.46(7.47)$ & 0.676
\end{tabular}

\section{Discussion:}

Family caregiving over a long period not only exacerbates the physical and mental problems of caregiver, but also aggravates the various domains of caregiver burden irrespective of nationality or socioeconomic status. ${ }^{9}$

This study is a cross-sectional study to determine the factors contributing to the caregiver burden in caregivers of patients with dementia. The study comprised 96 caregivers aged 20 or older who were the primary caregivers for demented older family members. Most of them (69.7\%) were females and (30\%) were males with mean age $(42.94) \pm 13.17$ years and this goes in accordance with Lin $\& \mathrm{Wu}^{8}$ who examined 956 caregivers and found out that $69.9 \%$ of them were females.

The most significant psychiatric consequence of dementia caregiving is high incidence of depression among caregivers. In this study we assessed depression in caregivers using Patient Health Questionnaire-9 (PHQ-9) and it showed that $(38.5 \%)$ of caregivers had moderate to severe depression, $(43.7 \%)$ had mild to moderate depression and (17.7\%) were with minimal depressive symptoms and this goes in accordance with other studies that reported depression to be present in $32 \%$ to $43 \%$ of dementia patients' caregivers ${ }^{10}$

Gender is an influence on roles and perceptions of caregiver burden, several studies have found that female caregivers tend to report more health problems and depressive symptoms than male caregivers ${ }^{10}$ and this agrees with our study as we found that females showed statistically significant depressive symptoms in comparison to males according to the PHQ-9 score and this may be explained by the female rule in the community which is affected by the community culture and education level as well. 
Yet, other studies found no gender effect on global measures of caregiver burden ${ }^{12}$ as there may be a lack of knowledge regarding men as caregivers since women have been thrust more in the role of caregiving, because women life expectancy is longer than that of men and because men generally marry younger women. Other studies ignored the non-spousal caregivers and didn't include adult child caregivers or other relative caregivers in addition to inclusion of informal caregivers of not only demented elderly but of other mentally ill persons and other physical disabilities and that caused the discrepancy in the results ${ }^{11}$

This study couldn't prove the presence of any statistically significant correlation between the caregivers' depressive symptoms and their marital status, financial status or their educational level which goes in accordance with Solomon \& Draine ${ }^{13}$, To'meh \& Al Tell $^{14}$ this can be explained by relating depressive symptoms to care recipients' factors such as their scores in ADL, IADL and their behavioral symptoms such as (agitation, crying, screaming, wandering ...etc).

\section{Conclusion:}

Caregivers of people with dementia, particularly women, are prone to depression.

\section{References}

1. Zarit S, Todd P \& Zarit J.Subjective burden of husbands and wives as caregivers: A longitudinal study. The Gerontologist.1986, 26, 260-266.

2. Russo J, Vitaliano PP, Brewer DD, Katon W, \& Becker J.Psychiatric disorders in spouse caregivers of care recipients with Alzheimer's disease and matched controls: A diathesis-stress model of psychopathology. Journal of Abnormal Psychology.1995, 104,197-204.

3. Gallagher D, Rose J, Rivera P, Lovett S, \& Thompson LW. Prevalence of depression in family caregivers. The Gerontologist.1989, 29, 449-456.

4. Campbell P, Wright J, Oyebode J, et al. Determinants of burden in those who care for someone with dementia. International Journal of Geriatric Psychiatry.2008, 23(10), 1078-1085.

5. Ory M, Hoffman R, Yee J, Tennsted S, Schulz R.Prevalence and impact of caregiving: a detailed comparison between dementia and nondementia caregivers. Gerontologist.1999, 39(2): 177-185.

6. Cornell LL. Taking reproduction seriously: marxism and the 'modern family' in China and Japan. In Social Structures and Human Lives, RileyMW, HuberBJ, HessBB (eds). Sage Publications: Newbury Park, CA;1988 101-114.

7. Kroenke K, Spitzer R L, Williams J B. The PHQ-9: validity of a brief depression severity measure. Journal of General Internal Medicine.2001, 16(9): 606-613

8. Kroenke K, Spitzer R, Williams W. The PHQ-9: Validity of a brief depression severity measure. JGIM, 2001, 16:606-616

9. Lin LN, Wu SC. Measurement structure of the caregiver burden scale: findings from a national community survey in Taiwan. Geriatr Gerontol Int.2014; 14: 176-184.

10. Waite A, Bobbington P, Skelton-Robinson M \& Orrell M (2004): Social factors and depression in carers of people with dementia. Int J Geriatr Psychiatry.2004, 19:582-587.

11. Gallicchio L, Siddiqi N, Langenberg P, Baumgarten M. Gender differences in burden and depression among informal caregivers of demented elders in the community. International Journal of Geriatric Psychiatry.2002, 17, 154-163.

12. Chumbler N, Grimm J, Cody M, \& Beck C. Gender, kinship, and caregiver burden: The case of community-dwelling, memoryimpaired seniors. International Journal of Geriatric Psychiatry.2003, 18, 722-732.

13. Solomon $P$, Draine $J$.Subjective burden among family members of mentally ill adults: Relation to stress, coping, and adaptation. American Journal of Orthopsychiatry.1995, 65, 419-427.

14. To'meh H, Al Tell . Family burden among caregivers of mentally ill patients in Nablus District. An Najah National University. Faculty of Graduate Studies.2013 